\title{
Article \\ Extraction and Study of Hypoglycemic Constituents from Myrica rubra Pomace
}

\author{
Guoli Chang ${ }^{1}$, Chenggang Cai ${ }^{1, * \mathbb{D}}$, Yannan Xiang ${ }^{1}$, Xiangjun Fang ${ }^{2}$ and Hailong Yang ${ }^{3, *}$ \\ 1 School of Biological and Chemical Engineering, Zhejiang University of Science and Technology, \\ Hangzhou 310023, China; 212003817003@zust.edu.cn (G.C.); 212103817019@zust.edu.cn (Y.X.) \\ 2 Institute of Food Science, Zhejiang Academy of Agricultural Sciences, Hangzhou 310023, China; \\ fangxj@zaas.ac.cn \\ 3 College of Life and Environmental Science, Wenzhou University, Wenzhou 325035, China \\ * Correspondence: ccg0516@zust.edu.cn or ccg0516@sina.com (C.C.); \\ yhl@wzu.edu.cn or yangh199@163.com (H.Y.); Tel.: +86-571-8507-0393 (C.C.); +86-577-8668-9079 (H.Y.)
}

Citation: Chang, G.; Cai, C.; Xiang, Y.; Fang, X.; Yang, H. Extraction and Study of Hypoglycemic Constituents from Myrica rubra Pomace. Molecules 2022, 27, 846. https://doi.org/ $10.3390 /$ molecules 27030846

Academic Editors:

Masahide Hamaguchi and Jianbo Xiao

Received: 20 December 2021

Accepted: 25 January 2022

Published: 27 January 2022

Publisher's Note: MDPI stays neutral with regard to jurisdictional claims in published maps and institutional affiliations.

Copyright: (c) 2022 by the authors. Licensee MDPI, Basel, Switzerland. This article is an open access article distributed under the terms and conditions of the Creative Commons Attribution (CC BY) license (https:// creativecommons.org/licenses/by/ $4.0 /)$.

\begin{abstract}
Myrica rubra pomace accounts for $20 \%$ of the fruit's weight that is not utilized when it is juiced. The pomace contains bioactive phenolic substances such as anthocyanins and flavonoids. To improve the utilization value of Myrica rubra pomace, an optimized extraction method for the residual polyphenols was developed using response surface methodology (RSM). The resulting extract was analyzed by high performance liquid chromatography (HPLC), and the in vitro hypoglycemic activity and antioxidant activity of the polyphenolic compounds obtained were also investigated. The optimum extraction conditions (yielding $24.37 \mathrm{mg} \cdot \mathrm{g}^{-1}$ total polyphenols content) were: extraction temperature $60{ }^{\circ} \mathrm{C}$, ultrasonic power $270 \mathrm{~W}$, ethanol concentration $53 \%$, extraction time $57 \mathrm{~min}$, and solid to liquid ratio 1:34. Four polyphenolic compounds were identified in the pomace extract by HPLC: myricitrin, cyanidin-O-glucoside, hyperoside, and quercitrin. DPPH and hydroxyl radical scavenging tests showed that the Myrica rubra polyphenols extract had strong antioxidant abilities. It is evident that the residual polyphenols present in Myrica rubra pomace have strong hypoglycemic activity and the juiced fruits can be further exploited for medicinal purposes.
\end{abstract}

Keywords: Myrica rubra residue; diabetes management; polyphenols; $\alpha$-Glucosidase inhibition; HPLC

\section{Introduction}

Diabetes mellitus is a chronic metabolic disease characterized by hyperglycemia, usually caused by insufficient insulin secretion or impaired insulin action, accompanied by disorders in the metabolism of three major nutrients: sugar, fat, and protein [1]. Diabetes can cause damage and lesions in many organs of the body, including the eyes, kidneys, blood vessels, heart, and brain, and there are more than 100 kinds of complications [2], which seriously affect the daily life and physical and mental health of patients. According to the International Diabetes Federation (IDF), the prevalence of adult diabetes globally reached 9.3\% in 2019, 438 million patients. China accounts for the largest grouping of diabetics, about 116 million. By 2045, nearly 700 million adults are projected to suffer from diabetes, worldwide [3]. Currently, approximately $90 \%$ of the patients clinically diagnosed with diabetes mellitus suffer from type II [4].

Controlling blood glucose levels is an effective way to reduce the effects of diabetes and the complications caused by hyperglycemia [5]. Most of the current drug-therapy glucose-lowering mechanisms for diabetes include targeting pancreatic $\beta$-cells, reducing pancreatic $\beta$-cell apoptosis, promoting $\beta$-cell proliferation and regeneration, and promoting insulin secretion. Other therapeutic approaches to managing diabetes include: increasing the number of insulin receptors or increasing their sensitivity to insulin, reducing hepatic glucose output, promoting sugar utilization by surrounding tissues and target organs, scavenging free radicals, reducing the expression of inflammatory factors and 
protecting pancreatic $\beta$-cells from inflammatory response damage, improving microcirculation, and inhibiting the activity of key enzymes, such as $\alpha$-glucosidase and $\alpha$-amylase [6]. At present, improving postprandial hyperglycemia is a key strategy for the treatment of diabetes and its complications. $\alpha$-glucosidase inhibitors, such as acarbose, miglitol tablets, and voglibose, mainly delay the absorption of glucose in the body and reduce postprandial hyperglycemia by inhibiting the activity of $\alpha$-glucosidase [7]. However, long-term administration of these hypoglycemic drugs can lead to serious gastrointestinal adverse effects, such as abdominal discomfort, diarrhea, and flatulence [8,9]. Therefore, many pharmaceutical developers are actively seeking safe, effective, and non-toxic alternatives. As an alternative to drug therapies, treating or controlling diabetes and preventing or delaying the occurrence of complications related to diabetes is possible by modifying diets and taking herbal medicines [10-12].

Myrica rubra (MR) is an endemic fruit in China that is cultivated in Zhejiang, Fujian, and Jiangsu provinces $[13,14]$. M. rubra contains bioactive substances, such as anthocyanins [15], flavonoids [16], and terpenoids [17], that can display free-radical scavenging antioxidant [18], anti-inflammatory [19], lipid improvement [20], cancer prevention [21], and antibacterial [22] activities. M. rubra can be consumed directly or processed into juices, fruit wines, fruit vinegars, beverages, etc. The pomace (residue) from juice extraction is mostly discarded as solid waste, leading to environmental pollution. It is also extremely wasteful because the residue is rich in polyphenols content, and it may also contain significant amounts of the bioactive ingredients; therefore, further study of $M$. rubra pomace is critically needed.

In this study, extraction optimization of active ingredients from M. rubra pomace by single-factor and RSM. The active ingredients in the extract were separated and identified by HPLC, then the in vitro antioxidant effect was also evaluated by the scavenging ability of 1,1-diphenyl-2-picylhydrazyl (DPPH) radicals and hydroxyl radicals and the in vitro hypoglycaemic effect was assessed by the $\alpha$-glucosidase inhibition assay. The results will be useful for further high-valued application of Myrica rubra pomace as a material to extract active ingredients and estimate their activities.

\section{Results}

\subsection{Single Factor Experimental Results}

\subsubsection{Effect of Sonication Power on Total Polyphenols Content}

The effect of sonication power on the total polyphenols content from MR powder extraction is shown as Figure 1. Total polyphenols content obtained increased from $150 \mathrm{~W}$ to $270 \mathrm{~W}$, with maximal extraction efficiency at $270 \mathrm{~W}\left(19.99 \mathrm{mg} \cdot \mathrm{g}^{-1}\right.$ obtained). Continuing to increase the ultrasonication power led to reduced extraction efficiency of polyphenols, mainly because the higher power created more cavitation bubbles [23]. Too many cavitation bubbles affects the propagation of ultrasound [24], which decreases overall extraction efficacy. Additionally, anthocyanin is susceptible to degradation when the sonication power is too high. Considering the extraction performance, anthocyanin preservation, and energy savings, $270 \mathrm{~W}$ was selected as the optimal ultrasonic power setting.

\subsubsection{Effect of Extraction Time on Total Polyphenols Content}

The relationship between extraction time and total polyphenols content is shown in Figure 2. Total polyphenols content did not fluctuate with time until the 90 min mark where the total polyphenols content decreased sharply. Prolonged ultrasonic treatment, which heats up the extraction mixture, may have accelerated the oxidation and destruction polyphenols, resulting in loss of total polyphenols extraction [25]. Therefore, $50 \mathrm{~min}$ was selected as the optimal extraction time from this study. 


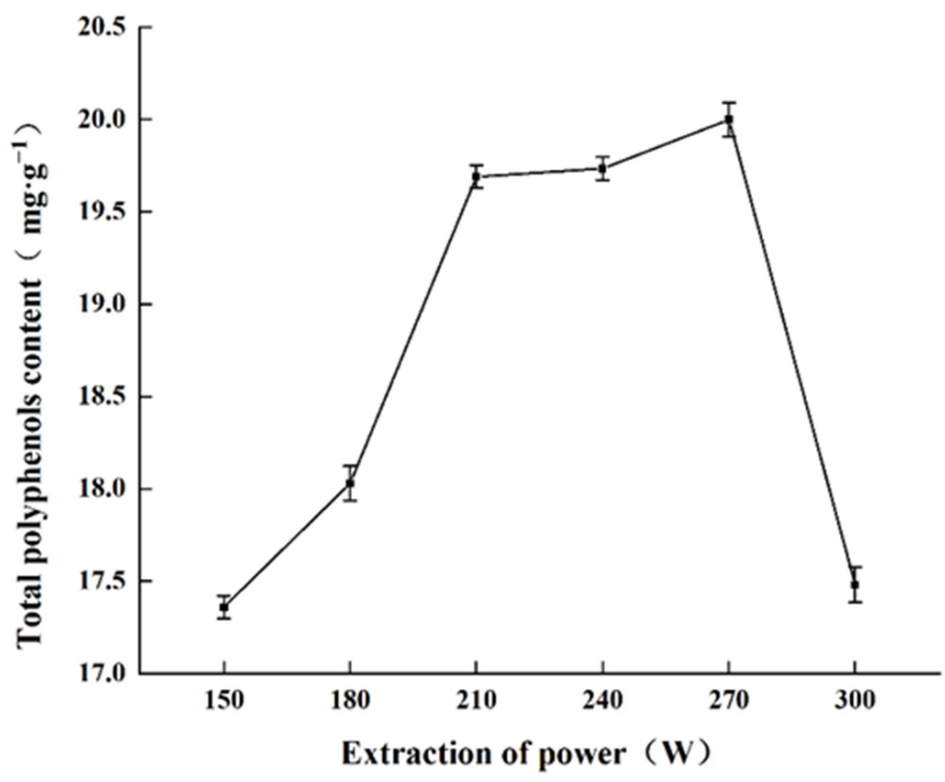

Figure 1. Effect of sonication power on the total polyphenols content obtained.

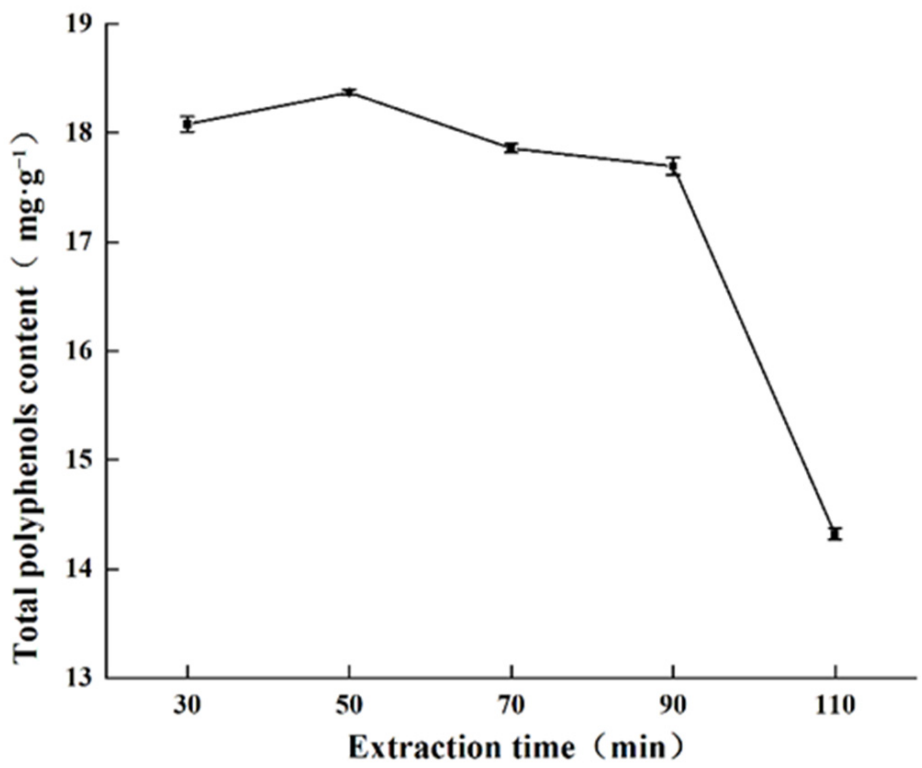

Figure 2. Effect of extraction time on total polyphenols content obtained.

\subsubsection{Effect of Solid to Liquid Ratio on Total Polyphenols Content}

The effects of various solid to liquid ratios on polyphenols extraction are shown in Figure 3. With increasing solid to liquid ratios, the total phenolic content gradually increased. When the solid to liquid ratio was 1:30, the total polyphenols content obtained was $21.02 \mathrm{mg} \cdot \mathrm{g}^{-1}$. Further increasing the solid to liquid ratio to $1: 50$ led to $21.71 \mathrm{mg} \cdot \mathrm{g}^{-1}$ total polyphenols extraction. While increasing the amount of solvent increased total polyphenols content extraction, minimizing the amount of solvent required for extraction aids in process efficiency because the extraction solvent must ultimately be removed. Therefore, solvent usage should be minimized to reduce the extraction cost from both a material and time perspective. Considering the decreasing gains from further increasing the amount of extraction solvent, the solid to liquid ratio of 1:30 was selected for further study. 


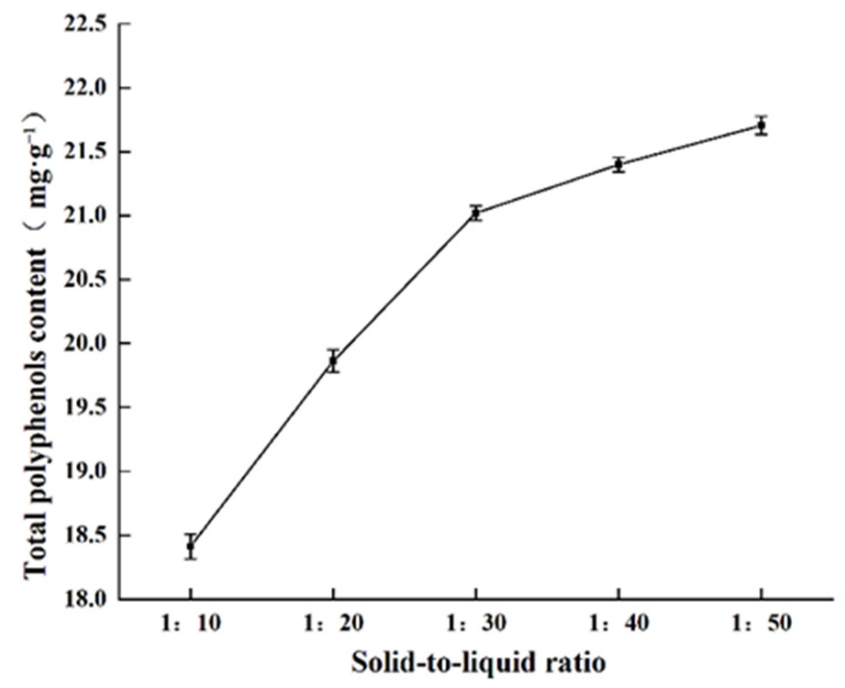

Figure 3. Effect of solid to liquid ratio on the total polyphenols content obtained.

\subsubsection{Effect of Ethanol Concentration on Total Polyphenols Content}

The effects of different ethanol concentrations on polyphenols extraction are shown in Figure 4. Extraction efficiency increased continuously as the percent ethanol increased, reaching a maximum of $20.22 \mathrm{mg} \cdot \mathrm{g}^{-1}$ with $40 \%$ ethanol. Thereafter, further increasing the ethanol concentration decreased total polyphenols extraction. Phenolic compounds are mainly distributed in the cytosol of plant vesicles. Water and low concentrations of ethanol can enter the cells, but high concentrations of ethanol can lead to denaturation of plant proteins and prevent the solubilization of polyphenols, thus affecting the extraction efficiency [26]. Therefore, $40 \%$ aqueous ethanol was selected as the optimal extraction solvent.

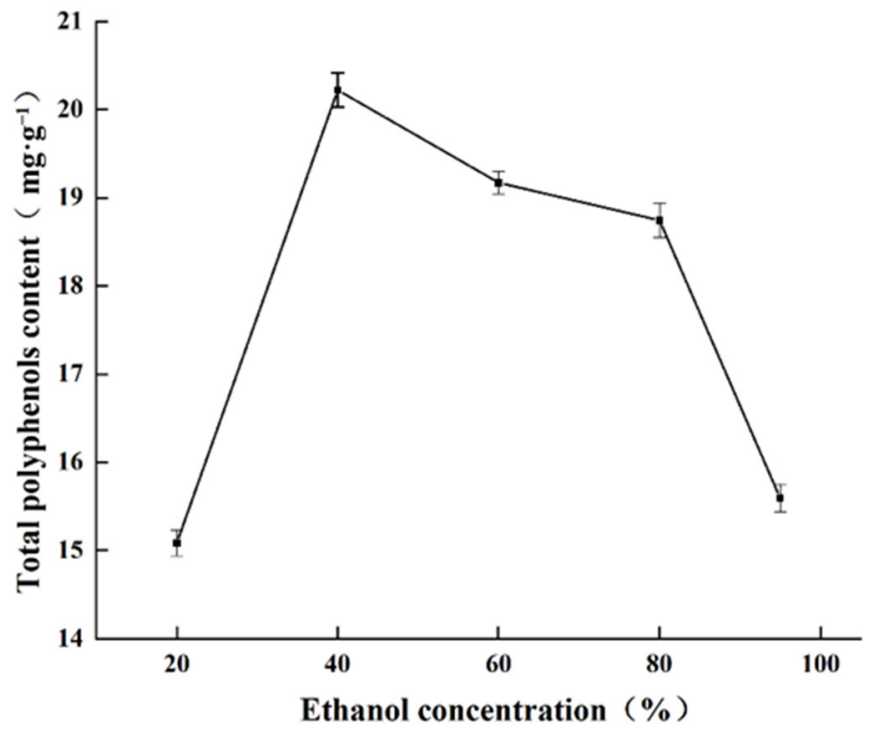

Figure 4. Effect of ethanol concentration on total polyphenols content obtained.

\subsection{Response Surface Modelling}

\subsubsection{Analysis of the Response Surface Model}

The MR powder extraction conditions were optimized using different combinations of variables according to the central composite design model in Table 1 . To evaluate the applicability of the optimized model, regression analysis and analysis of variance (ANOVA) tests were performed. 
Table 1. Response surface test design and MR powder extraction results.

\begin{tabular}{ccccc}
\hline Number & $\begin{array}{c}\text { Ethanol } \\
\text { Concentration (\%) }\end{array}$ & $\begin{array}{c}\text { Time } \\
(\mathbf{m i n})\end{array}$ & $\begin{array}{c}\text { Solid-to-Liquid } \\
\text { Ratio }\end{array}$ & $\begin{array}{c}\text { Total Polyphenols } \\
\text { Content (mg. } \mathbf{g}^{-1} \text { ) }\end{array}$ \\
\hline 1 & $20(-1)$ & $70(1)$ & $1: 20(-1)$ & 14.0994 \\
2 & $40(0)$ & 16.36 & $1: 30(0)$ & 19.5022 \\
3 & $40(0)$ & $50(0)$ & $1: 30(0)$ & 23.9611 \\
4 & $40(0)$ & $50(0)$ & $1: 30(0)$ & 23.0864 \\
5 & $73.64(1.682)$ & $50(0)$ & $1: 30(0)$ & 20.1641 \\
6 & $40(0)$ & $50(0)$ & $1: 30(0)$ & 21.224 \\
7 & $6.36(-1.682)$ & $50(0)$ & $1: 30(0)$ & 14.7639 \\
8 & $20(-1)$ & $30(-10$ & $1: 20(-1)$ & 13.8511 \\
9 & $60(1)$ & $70(1)$ & $1: 40(1)$ & 22.1833 \\
10 & $40(0)$ & $50(0)$ & $1: 30(0)$ & 23.3016 \\
11 & $60(1)$ & $70(1)$ & $1: 20(-1)$ & 21.0816 \\
12 & $60(1)$ & $30(-1)$ & $1: 40(1)$ & 20.6164 \\
13 & $40(0)$ & $50(0)$ & $1: 46.82(1.682)$ & 15.8053 \\
14 & $40(0)$ & $50(0)$ & $1: 13.18(-1.682)$ & 14.795 \\
15 & $20(-1)$ & $30(-1)$ & $1: 40(1)$ & 12.971 \\
16 & $20(-1)$ & $70(1)$ & $1: 40(10)$ & 18.5682 \\
17 & $40(0)$ & $50(0)$ & $1: 30(0)$ & 22.8778 \\
18 & $60(1)$ & $30(-1)$ & $1: 20(-1)$ & 22.6394 \\
19 & $40(0)$ & $50(0)$ & $1: 30(0)$ & \\
20 & $40(0)$ & 83.64 & $1: 30(0)$ & \\
& & $(1.682)$ & & \\
\hline
\end{tabular}

Design-expert software was used for quadratic regression fitting of the data in Table 1. The regression equation for total polyphenols content obtained was: total polyphenols content $\left(\mathrm{mg} \cdot \mathrm{g}^{-1}\right)=22.72+2.48 \mathrm{~A}+0.42 \mathrm{~B}+1.02 \mathrm{~B}+0.44 \mathrm{AB}+0.77 \mathrm{AC}-0.23 \mathrm{BC}-2.19 \mathrm{~A}^{2}$ $-0.92 B^{2}-1.93 C^{2}$.

The RSM test was performed on the experimental data and the applicability of the model was analyzed using linear regression and ANOVA (Table 2).

Table 2. ANOVA of the central composite design.

\begin{tabular}{ccccccc}
\hline Source & $\begin{array}{c}\text { Quadratic } \\
\text { Sum }\end{array}$ & $\begin{array}{c}\text { Degrees of } \\
\text { Freedom }\end{array}$ & $\begin{array}{c}\text { Mean } \\
\text { Square }\end{array}$ & F Value & $p$ Value & Significance \\
\hline Model & 223.38 & 9 & 24.82 & 9.31 & 0.0009 & $* *$ \\
A-Ethanol & 84.1 & 1 & 84.1 & 31.55 & 0.0002 & $* *$ \\
concentration & 2.36 & 1 & 2.36 & 0.88 & 0.3693 & \\
B-Time & & & & & & \\
C-Solid-to- & 14.17 & 1 & 14.17 & 5.32 & 0.0438 & $*$ \\
liquid & & & & & & \\
ratio & 1.57 & 1 & 1.57 & 0.59 & 0.4601 & \\
AB & 4.79 & 1 & 4.79 & 1.8 & 0.2098 & \\
AC & 0.42 & 1 & 0.42 & 0.16 & 0.6986 & $*$ \\
BC & 69.14 & 1 & 69.14 & 25.94 & 0.0005 & $*$ \\
A2 & 12.07 & 1 & 12.07 & 4.53 & 0.0592 & \\
B2 & 53.47 & 1 & 53.47 & 20.06 & 0.0012 & \\
C2 & 26.66 & 10 & 2.67 & & & \\
Residual error & 21.07 & 5 & 4.21 & 3.77 & 0.0858 & \\
Lack of fit & 5.59 & 5 & 1.12 & & & \\
Pure error & 250.03 & 19 & & & & \\
Total value & & & & & \\
\hline
\end{tabular}

Notice: ${ }^{* *}$ high significant effect, $p<0.01$; ${ }^{*}$ significant effect, $p<0.05 ; \mathrm{N}$ insignificant effect, $p>0.05$; $\mathrm{df}$, degrees of freedom, indicate number of items used; $F$ value, a test statistic that determines whether any item in the model is associated with a response, including block and factor items; Prob, probability, used to measure evidence against the null hypothesis. 
As seen in Table 2, the regression model obtained from the results of this experiment were significant $(p=0.0034<0.005)$ and the misfit error was not significant $(p=0.1996>0.05)$, which indicates that the unknown factors have less influence on the test results. The residuals were mainly caused by random errors, and the test results fit the model well [27]. The adjustment coefficient $\mathrm{R}^{2} \mathrm{Adj}$ in the model was $79.74 \%$, indicating that $79.74 \%$ of the variation in response values could be explained by the model. The correlation coefficient $\mathrm{R}^{2}$ was $89.34 \%$, and the signal-to-noise ratio was $8.981>4$, indicating that the model was highly credible and the model could be used for analysis and prediction. Ranking the importance of primary factors for polyphenols extraction from MR powder: ethanol concentration $>$ solid-liquid ratio $>$ time.

\subsubsection{Interactions of Different Experimental Factors on the Response Variables}

The response surface graph is a three-dimensional spatial surface graph of the response factors for each experimental factor that can visually depict the interaction between each experimental factor. The contour shape reflects the strength of the interaction: the more elliptical the contour shape, the stronger the interaction; and the rounder the contour shape, the weaker the interaction [28]. To better visualize the interaction of different experimental variables on polyphenols extraction, three response and contour plots were developed (Figure 5). The steeper the response surface and the stronger the contour lines, the more significant the influence of each factor is on the response value. The extreme values exist in the selected range, which is the highest point of the response surface and the center of the minimum ellipse of the contour line.

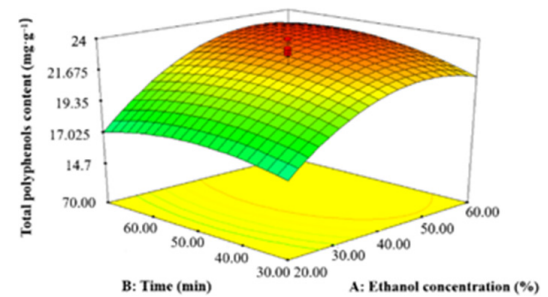

(a)

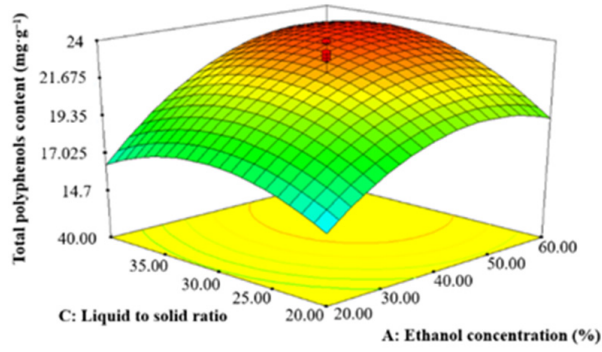

(c)

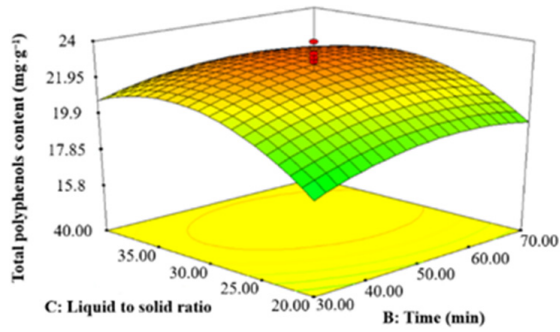

(e)

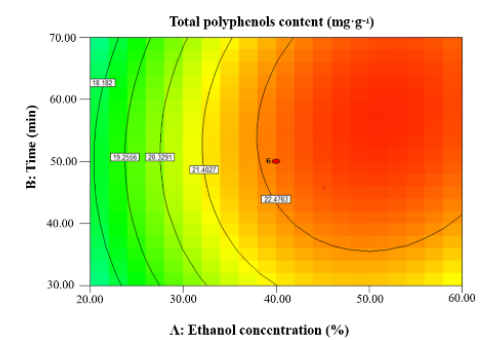

(b)

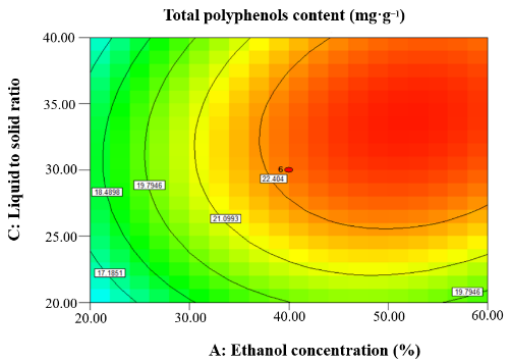

(d)

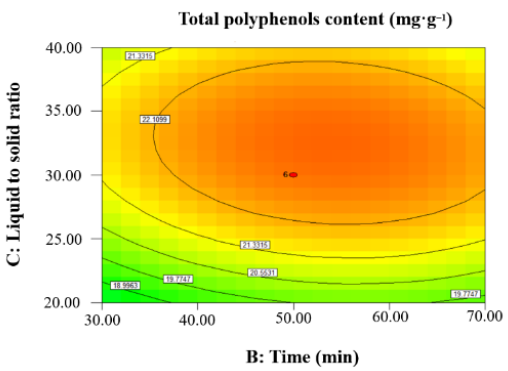

(f)

Figure 5. Response surface plots on total polyphenols extraction: $(\mathbf{a}, \mathbf{b})$ ethanol concentration and extraction time, $(\mathbf{c}, \mathbf{d})$ ethanol concentration and liquid to solid ratio, and $(\mathbf{e}, \mathbf{f})$ liquid to solid ratio and extraction time. 
Figure 5a or Figure 5b shows the effect of ethanol concentration on the extraction content: the highest polyphenols extraction was achieved with $50 \%$ aqueous ethanol, and the quantity of polyphenols extracted decreased with further increasing the ethanol concentration. As the ethanol concentration increased, more lipid-soluble and alcohol-soluble components reduced tissue permeability, thus decreasing the efficiency of polyphenols extraction $[29,30]$.

From Figure $5 c$ or Figure $5 d$, the larger the liquid to solid ratio, the larger the response value, indicating that the liquid to solid ratio has a large effect on the response value. As the solvent dosage increased, the effective contact area between the solvent and the substance increased, and the solute concentration difference became larger, which facilitated dissolution in the target molecules and promoted polyphenols extraction [31]. As noted in Section 2.1.4, polyphenols extraction decreased with increasing ethanol volume [32].

Figure 5 e or Figure $5 \mathrm{f}$ show that there is an optimal sonication time for polyphenols extraction from MR powder, because excessive ultrasonic treatment leads to decomposition and oxidation of the extracted polyphenols [33].

\subsubsection{Validation of Optimal Conditions}

From the RSM study, the optimal extraction conditions would be: ultrasonic power $270 \mathrm{~W}$, ethanol concentration $53.37 \%$, extraction time $56.84 \mathrm{~min}$, and solid to liquid ratio 1: 33.79. Under these conditions, predicted maximum polyphenols extraction from MR powder would be $23.82 \mathrm{mg} \cdot \mathrm{g}^{-1}$. To facilitate a practical study, the parameters were rounded to: solid to liquid ratio of 1:34 $\left(\mathrm{g} \cdot \mathrm{mL}^{-1}\right)$, ultrasonic time of $57 \mathrm{~min}$, and $53 \%$ aqueous ethanol. Under these conditions, $24.37 \mathrm{mg} \cdot \mathrm{g}^{-1}$ of polyphenols extraction was achieved, which was similar to the theoretical value. Therefore, the response surface optimization method can be used to optimize the extraction process of polyphenols from MR powder.

\subsection{Antioxidant Activity of the Polyphenols Extract from MR Powder}

The antioxidant activities of MR powder extract were expressed in terms of DPPH free radical scavenging capacity (Figure 6) and hydroxyl free radical scavenging capacity (Figure 7).

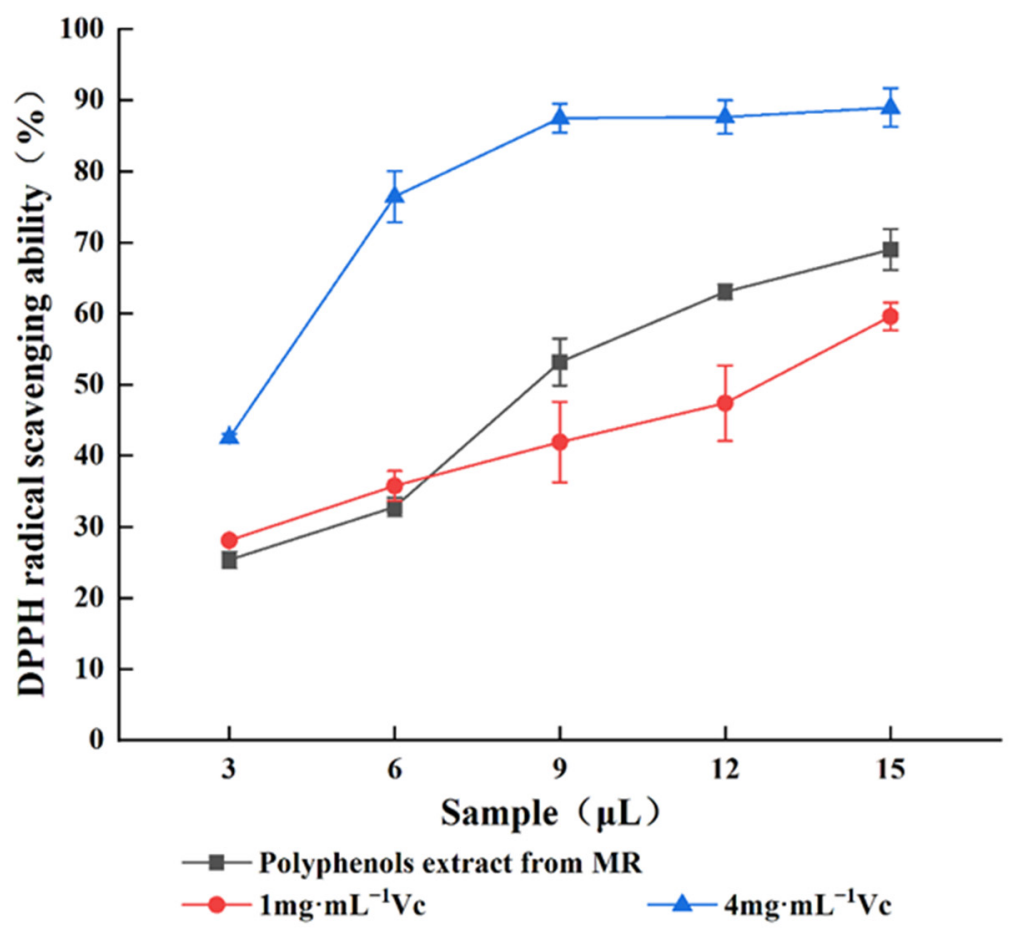

Figure 6. DPPH radical scavenging ability of polyphenols and $\mathrm{V}_{\mathrm{c}}$ from MR powder extract. 


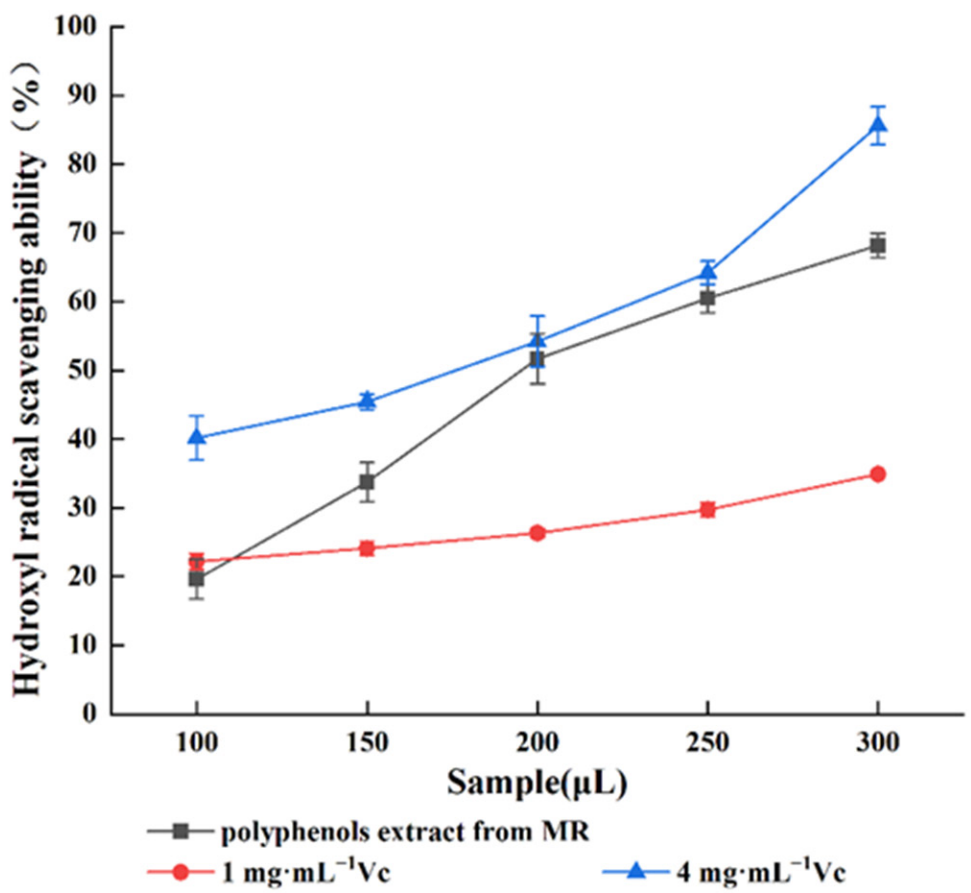

Figure 7. Scavenging ability of polyphenols and Vc hydroxyl radical in MR powder extract.

As can be seen in Figure 6, the scavenging effect of DPPH radicals by the MR powder extract gradually increased ( $25.38 \%$ to $69.03 \%$ ) with increasing sample dosage from 3 to $15 \mu \mathrm{L}$, showing a dose-dependent relationship. Compared with the control Vc, the scavenging ability of $\mathrm{M}$. rubra residue polyphenols extract ranged between $1 \mathrm{mg} \cdot \mathrm{mL}^{-1} \mathrm{Vc}_{\mathrm{c}}$ and $4 \mathrm{mg} \cdot \mathrm{mL}^{-1}$ Vc. A strong DPPH radical scavenging effect was observed with even a small amount of MR powder extract, which indicates that the polyphenols in M. rubra present strong antioxidant ability.

As shown in Figure 7, MR powder polyphenols extract and Vc displayed strong HO scavenging ability in a dose-dependent relationship. When $300 \mu \mathrm{L}$ was the selected dose, the hydroxyl radical scavenging ability was $34.92 \%$ for $1 \mathrm{mg} \cdot \mathrm{mL}^{-1} \mathrm{Vc}, 68.19 \%$ for MR powder polyphenols extract, and $85.62 \%$ for $4 \mathrm{mg} \cdot \mathrm{mL}^{-1} \mathrm{Vc}$. The hydroxyl radical scavenging ability of MR powder polyphenols extract was between $1 \mathrm{mg} \cdot \mathrm{mL}^{-1} \mathrm{Vc}$ and $4 \mathrm{mg} \cdot \mathrm{mL}^{-1} \mathrm{Vc}$, and showed an extremely strong increasing trend with increasing sample dosage.

\subsection{Liquid Chromatography Analysis}

In order to analysis the chemicals in MR powder extract, both the MR powder extract and the reference substances of Cyanidin-3-O-glucoside, Myricitrin, Hyperoside and Quercitrin were analyzed by HPLC, the results were shown in Figrue 8A and Figure 8B.

The maximum absorption wavelength of cyanidin-O-glucoside was $279.7 \mathrm{~nm}$, that of myricitrin was $352.5 \mathrm{~nm}$, that of hyperoside was $357.3 \mathrm{~nm}$, and that of quercitrin was $355 \mathrm{~nm}$. After a full wavelength scanning of the standards, the peak areas of the controls were read at the corresponding maximum absorption wavelengths, and the standard curves were plotted using concentration as the horizontal coordinate $(\mathrm{x})$ and the peak area $(\mathrm{y})$ as the vertical coordinate. Linear regression equations of cyanidin-o-glucoside, myricitrin, hyperoside and quercitrin were $y=16051 \mathrm{x}-15738\left(\mathrm{R}^{2}=0.9993\right), \mathrm{y}=21341 \mathrm{x}-149304$ $\left(R^{2}=0.9886\right), y=27830 x-139116\left(R^{2}=0.9954\right)$, and $y=27394 x-16759,\left(R^{2}=0.998\right)$, respectively. Having calibrated with standards, the concentrations of cyanidin-O-glucoside, myricitrin, hyperoside, and quercitrin obtained from the MR powder were $322.22 \mathrm{mg} \cdot \mathrm{L}^{-1}$, $23.00 \mathrm{mg} \cdot \mathrm{L}^{-1}, 17.81 \mathrm{mg} \cdot \mathrm{L}^{-1}$, and $24.35 \mathrm{mg} \cdot \mathrm{L}^{-1}$, respectively. The structure of cyanidin-oglucoside, myricitrin, hyperoside and quercitrin were listed as Appendix A (Figure A1). 

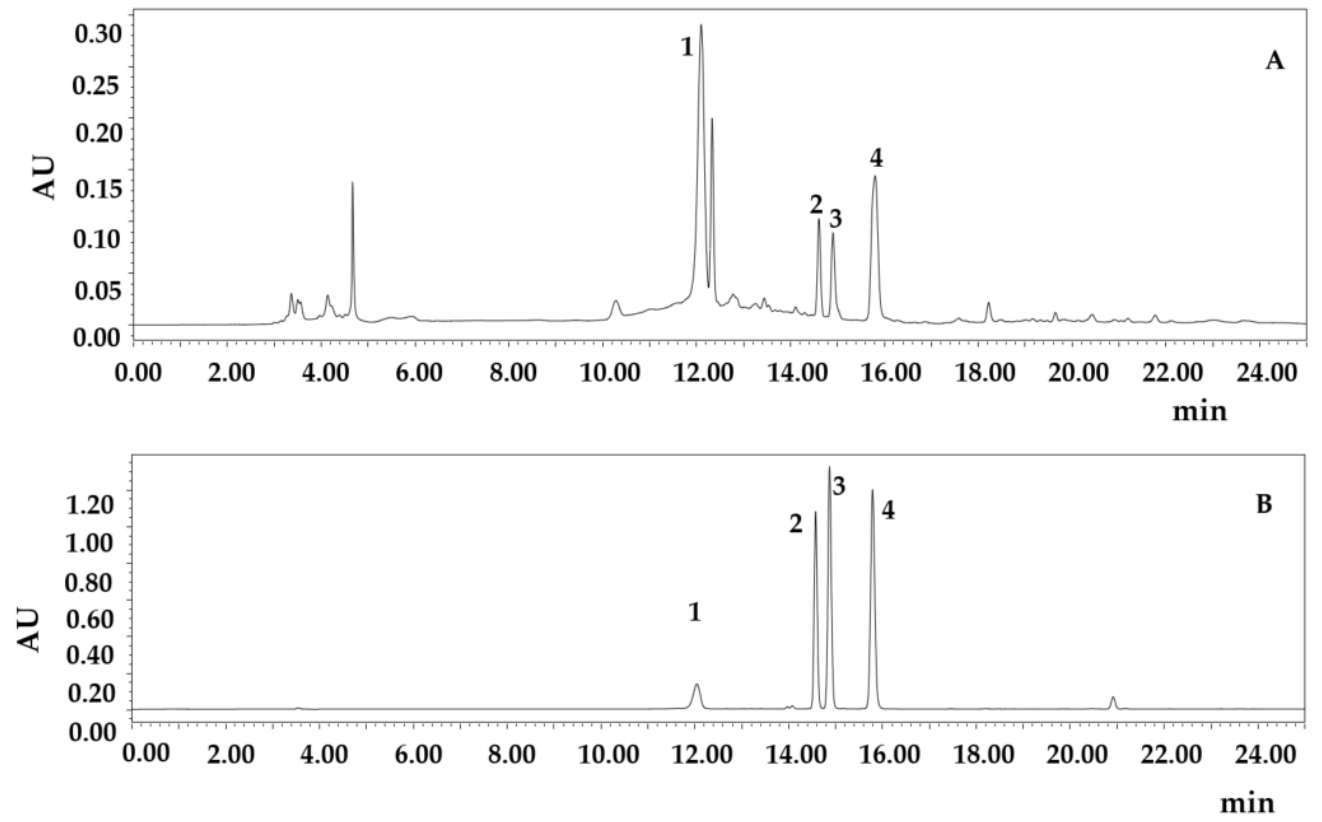

Figure 8. MR powder extract (A) and HPLC chromatograms of the reference substances (B). 1. Cyanidin-3-O-glucoside; 2. Myricitrin; 3. Hyperoside; and 4. Quercitrin.

\subsection{Analysis of $\alpha$-Glucosidase Inhibition Experiments}

As can be seen in Figure 9, the inhibition rate for each substance on $\alpha$-glucosidase increased with increasing dosage. At the final concentration of $1000 \mathrm{mg} \cdot \mathrm{L}^{-1}$, the positive control (acarbose) inhibited $\alpha$-glucosidase by $95.24 \%$, the polyphenols extract from MR powder inhibited $\alpha$-glucosidase by $97.57 \%$, cyanidin- $O$-glucoside, myricitrin, hyperoside, and quercitrin inhibited $\alpha$-glucosidase by $31.53 \%, 96.408 \%, 54.80 \%$, and 50.88\%, respectively. The $\mathrm{IC}_{50}$ values of acarbose, polyphenols from MR powder extract, cyanidinO-glucoside, myricitrin, hyperoside, and quercitrin were 231.41, 39.04, 3071.33, 221.33, 1056.20, and $1096.97 \mathrm{mg} \cdot \mathrm{L}^{-1}$, respectively. Thus, the MR powder extract demonstrated strong hypoglycemic effects, and the order of hypoglycemic strength of the active ingredients was myricitrin $>$ hyperoside $>$ quercitrin $>$ cyanidin-O-glucoside. Additionally, the hypoglycemic activity of the crude MR powder extract showed a positive correlation with the four flavonoid glycosides.

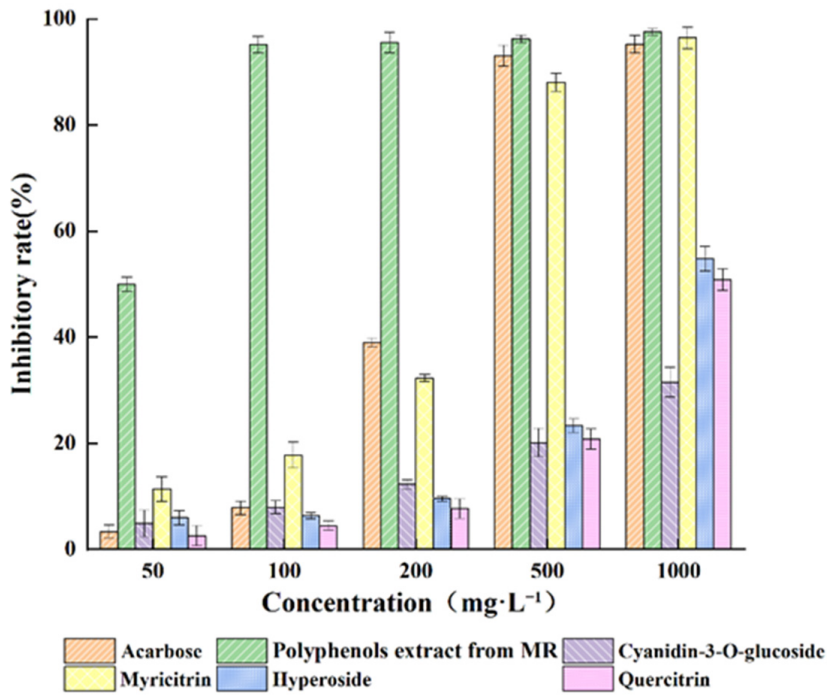

Figure 9. Inhibitory effects of MR powder extract on $\alpha$-glucosidase activity. 


\section{Materials and Methods}

\subsection{Materials}

Fresh Myrica rubra pomace was provided by a farmer located in Ningbo, Zhejiang Province, China. The pomace was dried at $40{ }^{\circ} \mathrm{C}$ overnight, then the residue was ground and filtered through a 40 -mesh screen and stored at $-20{ }^{\circ} \mathrm{C}$ until use (MR powder).

\subsection{Chemicals and Solvents}

1,1-diphenyl-2-picylhydrazyl (DPPH), Folin-Ciocalteu reagent, ascorbic acid (AA), rutin, $\alpha$-glucosidase, gallic acid (GA), cyanidin- $O$-glucoside, myricitrin, hyperoside, and quercitrin were purchased from Sigma Chemical Co. (St. Louis, MO, USA). All other chemicals, solvents, and reagents were analytical grade and obtained from Aladdin Chemical Corp. Ltd. (Shanghai, China).

\subsection{Extraction Procedure}

MR powder (500 mg) was accurately weighed and placed in stoppered glass test tubes. When ready, aqueous ethanol (various volumes and concentrations) was added and the stoppered tubes were placed in an ultrasonic water bath (KQ-400KDB, Kun Shan Ultrasonic Instruments Co., Ltd., Kunshan, China). After ultrasonic treatment, the tubes were centrifuged at $3000 \mathrm{rpm}$ for $5 \mathrm{~min}$ and the supernatant was collected for polyphenols content determination.

\subsection{Experimental Design and Analytical Methods}

\subsubsection{Single-Factor Extraction Experiments for Polyphenols MR Powder}

The effects of different ultrasonic powers $(150,180,210,240,270$, and $300 \mathrm{~W})$, aqueous ethanol concentrations $(20 \%, 40 \%, 60 \%, 80 \%$, and $95 \%)$, extraction time $(30,50,70,90$, and $110 \mathrm{~min}$ ), and solid-liquid ratios (1:10,1:20,1:30,1:40, and 1:50) on the polyphenols content in the extracts were investigated by conducting single-factor tests: in the development of one of the factors, the parameters of the other factors were taken as the middle value of the experimental design gradient, i.e., ultrasonic power of $240 \mathrm{~W}$, aqueous ethanol concentration of $60 \%$, extraction time of $70 \mathrm{~min}$, and solid-liquid ratios 1:30. Factors with significant effects on polyphenols content were selected for further study using response surface tests, which were repeated in triplicate.

\subsubsection{Response Surface Experiments for Polyphenols Extraction from MR Powder}

Based on the single-factor tests, the three factors of ethanol concentration (A), extraction time (B), and solid-liquid ratio $(\mathrm{C})$ were selected as the independent variables to optimize the polyphenols extraction content $(\mathrm{Y})$ by central composite design experiments using Design expert 7.0 software (Stat-Ease, Inc., Minneapolis, MN, USA). The experimental data were fitted and processed, and the test factors and levels are shown in Table 3.

Table 3. Factors and level of response surface test for polyphenols extraction from MR powder.

\begin{tabular}{ccccccc}
\hline \multirow{2}{*}{ Factors } & Code & \multicolumn{5}{c}{ Level } \\
\cline { 3 - 7 } & & $\mathbf{- 1 . 6 8 2}$ & $\mathbf{- 1}$ & $\mathbf{0}$ & $\mathbf{1}$ & $\mathbf{1 . 6 8 2}$ \\
\hline Ethanol concentration (\%) & $\mathrm{A}$ & 6.36 & 20 & 40 & 60 & 73.64 \\
Time (min) & $\mathrm{B}$ & 16.36 & 30 & 50 & 70 & 83.64 \\
Solid-to-liquid ratio & $\mathrm{C}$ & $1: 13.18$ & $1: 20$ & $1: 30$ & $1: 40$ & $1: 46.82$ \\
\hline
\end{tabular}

\subsubsection{Determination of Gallic Acid (GA) Content}

GA content was analyzed according to method of Francois [34] with slight modifications: extract solution $(0.5 \mathrm{~mL})$, distilled water $(9.5 \mathrm{~mL})$, and Folin-Ciocalteu reagent $\left(1 \mathrm{~mol} \cdot \mathrm{L}^{-1}, 1 \mathrm{~mL}\right)$ were sequentially added into a $25 \mathrm{~mL}$ volumetric flask and mixed thoroughly. Then, $7 \%$ sodium carbonate solution $(5 \mathrm{~mL})$ was added. The mixed solution was allowed to sit at room temperature for $1 \mathrm{~h}$ in the dark. Then, distilled water was added to 
the volumetric flask of $25 \mathrm{~mL}$ and the absorbance was analyzed at $750 \mathrm{~nm}$. GA standard solutions of $100,200,300,400$, and $500 \mathrm{mg} \cdot \mathrm{L}^{-1}$ were prepared and utilized to generate a calibration curve. The regression linear equation obtained was: $y=0.0014 x+0.062$, $\mathrm{R}^{2}=0.9946$. The concentration $\left(\mathrm{mg} \cdot \mathrm{g}^{-1}\right.$ ) was expressed as ratio of the determined results to fresh weight $(\mathrm{FW})$. All samples were analyzed in triplicate.

\subsubsection{Determination of Total Flavonoids}

The total flavonoid content was determined according to Hossain [35] with slight modifications. Seven $25 \mathrm{~mL}$ volumetric flasks were used to prepare 0.02, 0.04, 0.06, 0.08, 0.1, and $0.12 \mathrm{mg} \cdot \mathrm{mL}^{-1}$ rutin solutions using $30 \%$ ethanol as solvent. The above rutin standard solution $(5 \mathrm{~mL})$ was dispensed into seven stoppered test tubes; thereafter, $5 \%$ aqueous $\mathrm{NaNO}_{2}(0.3 \mathrm{~mL})$ was added to the serial dilutions and thoroughly mixed for $6 \mathrm{~min}$. Then, $10 \%$ aqueous $\mathrm{Al}\left(\mathrm{NO}_{3}\right)_{3}(0.3 \mathrm{~mL})$ was added to the serial dilutions and thoroughly mixed for $6 \mathrm{~min}$. Finally, the reaction was quenched with $1 \mathrm{M}$ aqueous $\mathrm{NaOH}(4 \mathrm{~mL})$ and distilled water $(0.4 \mathrm{~mL})$. After $15 \mathrm{~min}$, the absorbance value was measured at $510 \mathrm{~nm}$. The regression linear equation obtained for the rutin standard curve, utilized as a representative for total flavonoid content, was: $y=0.1502 x+0.0603, R^{2}=0.9978$. Samples of crude MR powder extract $(2 \mathrm{~mL})$ were similarly processed to determine flavonoid content. All experiments were performed in triplicate.

\subsubsection{Determination of Total Anthocyanin}

The total anthocyanin content was determined by the $\mathrm{pH}$ differential method using the method of Wang [36] with slight modifications. The sample solution $(0.5 \mathrm{~mL})$ was pipetted into a $10 \mathrm{~mL}$ tube and supplemented with $9.5 \mathrm{~mL}$ of $\mathrm{pH} 1.0(0.2 \mathrm{M} \mathrm{HCl}: 0.2 \mathrm{M}$ $\mathrm{KCl}=25: 67(V: V))$ and $\mathrm{pH} 4.5(0.2 \mathrm{M} \mathrm{HOAc:} 0.2 \mathrm{M} \mathrm{NaOAc}=63: 37(V: V))$ buffers, respectively, and equilibrated for $30 \mathrm{~min}$ with distilled water as a control. The absorbance values at $510 \mathrm{~nm}$ and $700 \mathrm{~nm}$ were measured with distilled water as control, and the experiments were performed in triplicate.

$$
\text { Total absorbance } \mathrm{A}=\frac{\mathrm{A} 510-\mathrm{A} 700}{\mathrm{~A}^{\prime} 510-\mathrm{A}^{\prime} 700}
$$

Anthocyanin content $\left(\mathrm{mg} \cdot \mathrm{L}^{-1}\right)=\frac{\mathrm{A} \times 1000 \times \mathrm{MW} \times \text { dilution ratio } \times \mathrm{V}}{\mathrm{L} \varepsilon \times \mathrm{m}}=\frac{\mathrm{A} \times 1000 \times 449.2 \times 20}{26900}$

where A510, A700 are absorbance values under $\mathrm{pH} 1.0 ; \mathrm{A}^{\prime} 510$ and $\mathrm{A}^{\prime} 700$ are the absorbance values at $\mathrm{pH} 4.5$; $\mathrm{L}$ is 1 , the width of the colorimetric cup; $\varepsilon, 26900$, the molar absorbance coefficient of cyanidin-3-O-glucoside in bayberry; 449.2 is the relative molecular weight of cyanidin-3-O-glucoside; $\mathrm{V}$ is $10 \mathrm{~mL}$; and $\mathrm{m}$ is sample mass.

\subsubsection{Total Phenolic Content Calculation}

Three representative polyphenols with highest content in the crude MR powder extract were selected: anthocyanins, flavonoids, and GA. Total phenolic content of the MR powder extract was the summation of these three measured substance values [37].

\subsubsection{DPPH Scavenging Capacity}

The method employed by Li [38] was modified by adding 3, 6, 9, 12, and $15 \mu \mathrm{L}$ of sample to $2 \mathrm{~mL}$ of deionized water, $4 \mathrm{~mL}$ of $0.1 \mathrm{mmol} \cdot \mathrm{L}^{-1} \mathrm{DPPH}$-methanol solution, and $450 \mu \mathrm{L}$ of $50 \mathrm{mmol} \cdot \mathrm{L}^{-1}$ Tris- $\mathrm{HCl}$ buffer ( $\mathrm{pH}$ 7.4). The reaction was carried out at $25^{\circ} \mathrm{C}$ for $30 \mathrm{~min}$ and the absorbance was measured at $517 \mathrm{~nm}$ using deionized water as the reference solution and $1 \mathrm{mg} \cdot \mathrm{mL}^{-1}$ ascorbic acid (Vitamin C, Vc) and $4 \mathrm{mg} \cdot \mathrm{mL}^{-1} \mathrm{Vc}_{\mathrm{c}}$ as the positive control.

$$
\text { DPPH radical scavenging ability }(\%)=\frac{A_{0}-\left(A_{1}-A_{2}\right)}{A_{0}} \times 100
$$


where $A_{0}$ is the absorbance of blank control solution; $A_{1}$ is the sample absorbance; and $A_{2}$ is the sample background absorbance without DPPH-methanol solution.

\subsubsection{Determination of Hydroxyl Radical Scavenging Ability}

Referring to the method of Tohidi [39], 100, 150, 200, 250, and $300 \mu \mathrm{L}$ of the samples were added to deionized water $(2 \mathrm{~mL})$, then $6 \mathrm{mM} \mathrm{H}_{2} \mathrm{O}_{2}(1.4 \mathrm{~mL})$, followed by $20 \mathrm{mM}$ sodium salicylate $(0.6 \mathrm{~mL})$ and $1.5 \mathrm{mM}$ aqueous ferrous sulphate $(2 \mathrm{~mL})$. The reaction vessel was placed in a constant water bath at $37^{\circ} \mathrm{C}$ for $1 \mathrm{~h}$. Deionized water was used as the reference solution and the absorbance was measured at $562 \mathrm{~nm}$ using $1 \mathrm{mg} \cdot \mathrm{mL}^{-1} \mathrm{Vc}$ and $4 \mathrm{mg} \cdot \mathrm{mL}^{-1} \mathrm{Vc}$ as the positive controls.

$$
\text { Hydroxyl radical scavenging ability }(\%)=\frac{\mathrm{A}_{0}-\left(\mathrm{A}_{1}-\mathrm{A}_{2}\right)}{\mathrm{A}_{0}} \times 100
$$

where $A_{0}$ is the absorbance of blank control solution; $A_{1}$ is the sample absorbance; and $A_{2}$ is the sample background absorbance without $\mathrm{H}_{2} \mathrm{O}_{2}$ solution.

\subsubsection{Liquid Chromatography Analysis}

The composition of the M. rubra residue polyphenols extract was analyzed using a Waters 2695 HPLC apparatus with Photodiode Array Detector 2998 (Waters, Framingham, MA, USA).

Chromatographic conditions: TechMate C18-ST column $(4.6 \times 250 \mathrm{~mm}, 5 \mu \mathrm{m}$, Techmate, Beijing, China), 100\% methanol (mobile phase A) and $0.1 \%$ formic acid water (mobile phase B). Gradient elution program: 0-5 min, 20\% A; 5-10 $\mathrm{min}, 20 \%$ to $60 \% \mathrm{~A} ; 10-13 \mathrm{~min}$, $60 \% \mathrm{~A} ; 13-15 \mathrm{~min}, 60 \%$ to $80 \% \mathrm{~A} ; 15-20 \mathrm{~min}, 80 \% \mathrm{~A} ; 20-23 \mathrm{~min}, 80 \%$ to $20 \% \mathrm{~A} ; 23-25 \mathrm{~min}$, $20 \% \mathrm{~A}$; flow rate, $0.8 \mathrm{~mL} \cdot \mathrm{min}^{-1}$; detection wavelength, $220 \sim 400 \mathrm{~nm}$ full wavelength scan; column temperature, $35^{\circ} \mathrm{C}$; and injection volume, $10 \mu \mathrm{L}$.

Preparation of mixed control solution: $10 \mathrm{mg}$ of cyanidin-O-glucoside, myricitrin, hyperoside, and quercitrin were weighed precisely, placed in a $10 \mathrm{~mL}$ volumetric flask, mixed with methanol, and then diluted into mixed control solutions with mass concentrations of $5,10,20,50,100$, and $200 \mathrm{mg} \cdot \mathrm{L}^{-1}$, respectively.

Sample preparation: $1 \mathrm{~mL}$ of MR powder polyphenols extract, obtained from the best extraction conditions as determined from the response surface test experiments, was passed through a $0.45 \mu \mathrm{m}$ syringe filter (nylon 66) and stored in the autosampler vial.

\subsubsection{0. $\alpha$-Glucosidase Inhibition Experiment}

The inhibitory effect of the crude MR powder extracts on $\alpha$-glucosidase was determined using 4-nitro- $\alpha$-D-glucopyranoside (PNPG) as a substrate. The studies for $\alpha$ glucosidase inhibition followed the method of Yao [40] with slight modifications. Experiments were performed in 96-well plates. $\alpha$-glucosidase $\left(0.32 \mathrm{U} \cdot \mathrm{mL}^{-1}, 20 \mu \mathrm{L}\right)$ and various concentrations sample solution $(20 \mu \mathrm{L})$ were incubated in $100 \mu \mathrm{L}$ phosphate buffer ( $\mathrm{pH}$ 6.8) at $37^{\circ} \mathrm{C}$ for $10 \mathrm{~min}$, then PNPG $\left(20 \mu \mathrm{L}, 2.5 \mathrm{mmol} \cdot \mathrm{L}^{-1}\right)$ was added. The plate was incubated at $37^{\circ} \mathrm{C}$ for $15 \mathrm{~min}$. Reactions were terminated with $40 \mu \mathrm{L} 0.2 \mathrm{M} \mathrm{NaOH}$. The absorbance was measured at $405 \mathrm{~nm}$. The blank and background controls were specific wells within the plate. Acarbose was used as a positive control. Inhibitor concentration of $50 \%\left(\mathrm{IC}_{50}\right)$ was determined when $\alpha$-glucosidase activity was inhibited $50 \%$. The inhibition rate of $\alpha$-glucosidase and $\mathrm{IC}_{50}$ values of each sample were calculated as follows:

$$
\alpha-\text { glucosidase inhibition rate }(\%)=\frac{A_{b}-\left(A_{s}-A_{0}\right)}{A_{b}} \times 100
$$

where $A_{b}$ is the absorption value of the control group; $A_{s}$ is the absorbance value of sample group; and $\mathrm{A}_{0}$ is the absorption value of the background group. 


\subsubsection{Statistical Analysis}

RSM experiments were conducted according to Design expert 7.0 software (Stat-Ease, Inc., Minneapolis, MN, USA). Each experimental data point in this paper is represented as mean \pm standard deviation (SD) of three independent replicates. The significant differences among means were identified by one-way analysis of variance (ANOVA) and a leastsignificant-difference (LSD) test at $p<0.05$, conducted with the SPSS 20.0 software package (SPSS Inc., Chicago, IL, USA).

\section{Conclusions}

In this study, optimal polyphenols extraction from dried M. rubra pomace were obtained after single factor design and response surface methodology experiments. The best extraction conditions for polyphenols were: $60^{\circ} \mathrm{C}, 270 \mathrm{~W}$ ultrasonic power, $53 \%$ ethanol concentration, 57 min ultrasonic time, and 1:34 solid to liquid ratio. The polyphenol content extracted was $24.37 \mathrm{mg} \cdot \mathrm{g}^{-1}$. MR powder extract demonstrated strong radical scavenging abilities (both DPPH radicals and hydroxyl radicals), stronger than $1 \mathrm{mg} \cdot \mathrm{mL}^{-1} \mathrm{Vc}$ and close to $4 \mathrm{mg} \cdot \mathrm{mL}^{-1} \mathrm{Vc}$ under the same conditions. HPLC studies confirmed the presence of four hypoglycemic substances that could inhibit the activity of $\alpha$-glucosidase were present in the MR powder extract: cyanidin-o-glucoside, myricitrin, hyperoside, and quercitrin. The $\mathrm{IC}_{50}$ values were compared, and the order of the hypoglycemic effect of the polyphenols from MR powder extract compared with the four substances and acarbose were MR powder extract $>$ myricitrin $>$ acarbose $>$ hyperoside $>$ quercitrin $>$ cyanidin-O-glucoside.

Myrica rubra polyphenols demonstrate good antioxidant and hypoglycemic activities; future work will be carried out to explore the active mechanism of the extract polyphenols in vivo, and to compare the single or synergistic effects among the four identified ingredients of myricitrin, cyanidin-O-glucoside, hyperoside, and quercitrin. The results will be helpful for the development and utilization of Myrica rubra pomace resources.

Author Contributions: Conceptualization, C.C. and H.Y.; methodology, G.C.; software, X.F.; validation, G.C. and C.C.; formal analysis, Y.X.; investigation, G.C. and Y.X.; resources, X.F.; data curation, G.C.; writing-original draft preparation, G.C.; writing-review and editing, G.C. and C.C.; visualization, H.Y.; supervision, C.C.; project administration, H.Y.; funding acquisition, H.Y. All authors have read and agreed to the published version of the manuscript.

Funding: This research was funded by the Key Research and Development Program of Zhejiang Province (2020C02038) and Zhejiang Basic Public Welfare Research Project (No. LGF19C200002).

Institutional Review Board Statement: Not applicable.

Informed Consent Statement: Not applicable.

Data Availability Statement: All data are included in this manuscript.

Conflicts of Interest: The authors declare no conflict of interest.

Sample Availability: Not applicable.

\section{Appendix A}

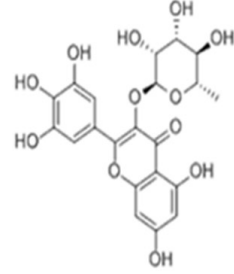

myricitrin

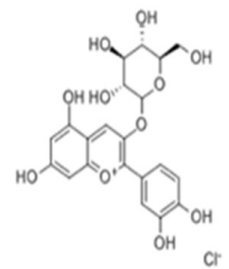

cyanidin-O-glucoside

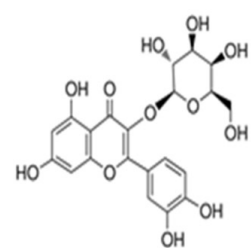

quercitrin

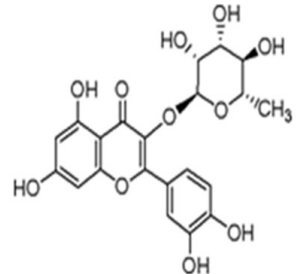

hyperoside

Figure A1. Molecular structure of four hypoglycaemic components of Myrica rubra pomace. 


\section{References}

1. Xu, L.N.; Li, Y.; Dai, Y.; Peng, J.Y. Natural products for the treatment of type 2 diabetes mellitus: Pharmacology and mechanisms. Pharmacol. Res. 2018, 30, 451-465. [CrossRef]

2. Wu, Y.L.; Ding, Y.P.; Yoshimasa, T.; Zhang, W. Risk Factors Contributing to Type 2 Diabetes and Recent Advances in the Treatment and Prevention. Int. J. Med. Sci. 2014, 11, 1185-1200. [CrossRef]

3. Saeedi, P.; Petersohn, I.; Salpea, P.; Malanda, B.; Karuranga, S.; Unwin, N.; Colagiuri, S.; Guariguata, L.; Motala, A.A.; Ogurtsova, K.; et al. Global and regional diabetes prevalence estimates for 2019 and projections for 2030 and 2045: Results from the International Diabetes Federation Diabetes Atlas. Diabetes Res. Clin. Pract. 2019, 157, 107843. [CrossRef]

4. $\quad$ Liao, Z.Z.; Zhang, J.Y.; Liu, B.; Yan, T.X.; Xu, F.X.; Xiao, F.; Wu, B.; Bi, K.S.; Jia, Y. Polysaccharide from okra (Abelmoschus esculentus (L.) Moench) improves antioxidant capacity via PI3K/AKT pathways and Nrf2 Translocation in a type 2 diabetes model. Molecules 2019, 24, 1906. [CrossRef]

5. Mertes, G. Safety and efficacy of acarbose in the treatment of Type 2 diabetes: Data from a 5-year surveillance study. Diabetes Res. Clin. Pract. 2001, 52, 193-204. [CrossRef]

6. Zhang, M.; Kou, X.J. Analysis of the mechanism of natural products on lowering blood glucose of type 2 diabetes mellitus. Chin. Bull. Life Sci. 2021, 33, 667-676.

7. van de Laar, F.A.; Lucassen, P.L. $\alpha$-Glucosidase Inhibitors for Patients with Type 2 Diabetes: Response to Hanefeld et al. Diabetes Care 2005, 28, 154-163. [CrossRef]

8. Xu, Y.; Xie, L.H.; Xie, J.H.; Liu, Y.; Chen, W. Pelargonidin-3-O-rutinoside as a novel $\alpha$-glucosidase inhibitor for improving postprandial hyperglycemia. Chem. Commun. 2019, 55, 39-42. [CrossRef]

9. Lee, N.J.; Norris, S.L.; Thakurta, S. Efficacy and harms of the hypoglycemic agent pramlintide in diabetes mellitus. Ann. Fam. Med. 2010, 8, 542-549. [CrossRef]

10. Sievenpiper, J.L.; Dworatzek, P.D.N. Food and dietary pattern-based recommendations: An emerging approach to clinical practice guidelines for nutrition therapy in diabetes. Can. J. Diabetes 2013, 37, 51-57. [CrossRef]

11. Arbatskaya, H.Y.; Ignatova, N.G.; Moldovanova, M.V.; Melnikova, E.P.; Kandalina, V.V. The role of dietotherapy in prevention of a diabetic fetopathy at women with gestational diabetes mellitus. J. Obstet. Women's Dis. 2013, 62, 9-15. [CrossRef]

12. Meng, J.N.; Zhu, Y.F.; Ma, H.X.; Wang, X.B.; Zhao, Q.P. The role of traditional Chinese medicine in the treatment of cognitive dysfunction in type 2 diabetes. J. Ethnopharmacol. 2021, 280, 114464. [CrossRef]

13. Zhang, Y.L.; Li, S.; Yin, C.P.; Jiang, D.H.; Yan, F.F.; Xu, X. Response surface optimization of aqueous enzymatic oil extraction from bayberry (Myrica rubra) kernels. Food Chem. 2012, 135, 304-308. [CrossRef]

14. Fang, Z.X.; Bhesh, B. Comparing the efficiency of protein and maltodextrin on spray drying of bayberry juice. Food Res. Int. 2012, 48, 478-483. [CrossRef]

15. Fang, Z.X.; Zhang, M.; Wang, L.X.; Sun, J.C. Identification of anthocyanin in Bayberry (Myrica rubra Sieb. et Zucc.) by HAPLCDAD-ESIMS and GC. J. Food Drug Anal. 2006, 14, 8. [CrossRef]

16. Kim, H.H.; Oh, M.H.; Park, K.J.; Heo, J.H.; Lee, M.W. Anti-inflammatory activity of sulfate-containing phenolic compounds isolated from the leaves of Myrica rubra. Fitoterapia 2014, 92, 188-193. [CrossRef]

17. Sakurai, N.; Yaguchi, Y.; Inoue, T. Triterpenoids from Myrica rubra. Phytochemistry 1986, 26, 217-219. [CrossRef]

18. Xia, W.; Gong, E.S.; Lin, Y.Y.; Li, T.; Zheng, B.S.; Liu, R.H. Comparison of phytochemical profiles, antioxidant and antiproliferative activities in Chinese bayberry (Myrica rubra Sieb. et Zucc.) fruits. J. Food Sci. 2021, 86, 4691-4703. [CrossRef]

19. Lin, K.H.; Lu, C.P.; Chao, J.W.; Yu, Y.P. Antioxidant properties and anti-inflammatory effects of the hydroethanolic extracts of two varieties of bayberry fruit (Myrica rubra Sieb et Zucc.) prepared by stirring and ultrasonic methods. Not. Bot. Horti Agrobot. Cluj-Napoca 2019, 47, 634-642. [CrossRef]

20. He, K.; Li, X.G.; Xiao, Y.B.; Yong, Y.; Zhang, Z.Q.; Li, S.P.; Zhou, T.M.; Yang, D.Q.; Gao, P.C.; Xin, X.L. Hypolipidemic effects of Myrica rubra extracts and main compounds in C57BL/6j mice. Food Funct. 2016, 7, 3505-3515. [CrossRef]

21. Zhang, Y.; Chen, S.; Wei, C.; Rankin, G.O.; Rojanasakuld, Y.; Ren, N.; Ye, X.Q.; Chen, Y.C. Dietary compound proanthocyanidins from Chinese bayberry (Myrica rubra Sieb. et Zucc.) leaves inhibit angiogenesis and regulate cell cycle of cisplatin-resistant ovarian cancer cells via targeting Akt pathway. J. Funct Foods 2018, 40, 573-581. [CrossRef]

22. Ju, J.; Yao, W.R.; Sun, S.L.; Guo, Y.H.; Cheng, Y.L.; Qian, H.; Xie, Y.F. Assessment of the antibacterial activity and the main bacteriostatic components from bayberry fruit extract. Int. J. Food Prop. 2018, 21, 1043-1051. [CrossRef]

23. Qua, W.J.; Sehemu, R.M.; Feng, Y.T.; Shi, S.Q.; Wang, J.; Ma, H.L.; Venkitasamy, C. Sonochemical effect of flat sweep frequency and pulsed ultrasound (FSFP) treatment on stability of phenolic acids in a model system. Ultrason. Sonochem. 2017, 39, 707-715.

24. Sun, Y.J.; Ma, G.P.; Ye, X.Q.; Kakuda, Y.; Meng, R.F. Stability of all-trans-beta-carotene under ultrasound treatment in a model system: Effects of different factors, kinetics and newly formed compounds. Ultrason. Sonochem. 2010, 17, 654-661. [CrossRef]

25. Wang, P.X.; Cheng, C.X.; Ma, Y.Q.; Jia, M. Degradation behavior of polyphenols in model aqueous extraction system based on mechanical and sonochemical effects induced by ultrasound. Sep. Purif. Technol. 2020, 247, 116967. [CrossRef]

26. Brglez, M.E.; Knez, H.M.; Škerget, M.; Knez, Z.; Bren, U. Polyphenols: Extraction methods, antioxidative action, bioavailability and anticarcinogenic effects. Molecules 2016, 21, 901. [CrossRef]

27. Tian, Y.; Zeng, H.L.; Xu, Z.B.; Zheng, B.D.; Lin, Y.X.; Gan, C.J.; Lo, Y.M. Ultrasonic-assisted extraction and antioxidant activity of polysaccharides recovered from white button mushroom (Agaricus bisporus). Carbohyd. Polym. 2012, 88, 522-529. [CrossRef] 
28. Zheng, S.Y.; Zhu, Y.P.; Jiao, C.Y.; Shi, M.Y.; Wei, L.P.; Zhou, Y.; Jin, Q.; Cai, Y.P. Extraction and analysis of gigantol from Dendrobium officinale with response surface methodology. Molecules 2018, 23, 818. [CrossRef]

29. Schmid, R. Recent advances in the description of the structure of water, the hydrophobic effect, and the like-dissolves-like rule. Mon. für Chem. 2001, 132, 1295-1326. [CrossRef]

30. Liyana-Pathirana, C.; Shahidi, F. Optimization of extraction of phenolic compounds from wheat using response surface methodology. Food Chem. 2005, 93, 47-56. [CrossRef]

31. Hayat, K.; Hussain, S.; Abbas, S.; Farooq, U.; Ding, B.M.; Xia, S.Q.; Jia, C.S.; Zhang, X.M.; Xia, W.S. Optimized microwave-assisted extraction of phenolic acids from citrus mandarin peels and evaluation of antioxidant activity in vitro. Sep. Purif. Technol. 2009, 70, 63-70. [CrossRef]

32. Prasad, K.N.; Yang, E.; Yi, C.; Zhao, M.M.; Jiang, Y.M. Effects of high pressure extraction on the extraction yield, total phenolic content and antioxidant activity of longan fruit pericarp. Innov. Food Sci Emerg. 2009, 10, 155-159. [CrossRef]

33. Roriz, C.L.; Barros, L.; Prieto, M.A.; Morales, P.; Ferreira, I.C.F.R. Floral parts of Gomphrena globosa L. as a novel alternative source of betacyanins: Optimization of the extraction using response surface methodology. Food Chem. 2017, 229, 223-234. [CrossRef] [PubMed]

34. Senejoux, F.; Demougeot, C.; Kerram, P.; Aisa, H.A.; Berthelot, A.; Bévalot, F.; Girard-Thernier, C. Bioassay-guided isolation of vasorelaxant compounds from Ziziphora clinopodioides Lam. (Lamiaceae). Fitoterapia 2012, 83, 377-382. [CrossRef]

35. Hossain, M.A.; Rahman, S.M.M. Rahman Total phenolics, flavonoids and antioxidant activity of tropical fruit pineapple. Food Res. Int. 2011, 44, 672-676. [CrossRef]

36. Wang, W.D.; Xu, S.Y. Degradation kinetics of anthocyanins in blackberry juice and concentrate. J. Food Eng. 2007, 82, 271-275. [CrossRef]

37. Zheng, L.Q.; Ding, Z.S.; Zhang, M.; Sun, J.C. Microencapsulation of bayberry polyphenols by ethyl cellulose: Preparation and characterization. J. Food Eng. 2011, 104, 89-95. [CrossRef]

38. Li, W.; Zhang, X.Y.; He, Z.Q.; Chen, Y.J.; Li, Z.Y.; Meng, T.M.; Li, Y.F.; Cao, Y. In vitro and in vivo antioxidant activity of eucalyptus leaf polyphenols extract and its effect on chicken meat quality and cecum microbiota. Food Res. Int. 2020, 136, 109302. [CrossRef]

39. Tohidi, B.; Rahimmalek, M.; Arzani, A. Essential oil composition, total phenolic, flavonoid contents, and antioxidant activity of Thymus species collected from different regions of Iran. Food Chem. 2017, 220, 153-161. [CrossRef]

40. Yao, Y.; Sang, W.; Zhou, M.; Ren, G.X. Antioxidant and $\alpha$-glucosidase inhibitory activity of colored grains in China. J. Agric. Food. Chem. 2010, 58, 770-774. [CrossRef] 